\title{
SOBRE PERMISOS EN EL DERECHO
}

\section{Presentación}

ras haber abordado en trabajos anteriores los problemas de las normas de mandato -reglas y principios- (Atienza-Ruiz Manero, 1991, 1992, 1993) y de las reglas que confieren poderes (Atienza-Ruiz Manero, 1994) nos proponemos ahora examinar la cuestión de las normas permisivas. Procederemos, para ello, a dar cuenta (I) de las que son, a nuestro juicio, las posiciones capitales al respecto en la teoría del Derecho contemporánea, para exponer después (II) nuestra propia concepción, cuyo eje central viene a ser la necesidad de distinguir, en relación con los permisos, entre tres contextos: el de las reglas regulativas de la conducta «natural», el de las reglas que confieren poderes y el de los principios jurídicos.

\section{Los permisos en la teoría del derecho contemporánea}

La cuestión de la existencia o no de normas permisivas es uno de los problemas más debatidos en la teoría del Derecho. Naturalmente, esta cuestión no equivale a la de si existen o no en los sistemas jurídicos enunciados del tipo «Pp» $\mathrm{O}$ «Fp». Obviamente, enunciados de este tipo son comunes en los sistemas jurídicos. Los problemas que hacen dudar de la existencia de normas permisivas (o, si se quiere, de la necesidad de la categoría «normas permisivas») son más bien los dos siguientes:

1) Es un lugar común entender que la función más primaria de cualquier sistema normativo es la de guiar la conducta humana. En el caso de las normas de mandato, esta función de guía de la conducta se lleva a cabo estipulando, bien la obligación de realizar una 
determinada acción $\mathrm{p}$ en un determinado caso $q$ (o, lo que es lo mismo, la prohibición de omitir realizar $p$ en $q$ ), bien la prohibición de realizar $p$ en q (o, lo que es lo mismo, la obligación de omitir $p$ en $q$ ). Esto es, las normas de mandato, que pueden expresarse bajo la forma de obligaciones o de prohibiciones, ordenan, bien realizar una determinada acción, bien omitirla y, así, deslindan la esfera de lo lícito de la de lo ilícito. Por el contrario, las normas permisivas -entendiendo por tales las que permiten, en un determinado caso $q$, tanto la realización como la omisión de una determinada acción $p$ - no ordenan nada. Pues bien: cuando nos encontramos frente a una norma de este tipo, frente a una norma que permite la realización y también la omisión de $p$ en el caso $q$ ¿la situación es pragmáticamente equivalente a la que se daría en el supuesto de que no hubiera ni una norma que prohibiera ni una norma que obligara a realizar $p$ en $q$ ? ¿Introduce la supuesta norma permisiva algo que no se dé en la mera ausencia de norma o más bien aquélla es pragmáticamente irrelevante?

2) En la medida en que la supuesta norma permisiva no sea pragmáticamente irrelevante ¿lo que ella introduce es algo distinto de la formulación indirecta o de la derogación de normas de mandato, esto es, de obligaciones o prohibiciones?

1. La irrelevancia práctica de las normas permisivas. La categoría de «normas permisivas» es innecesaria. Echave-Urquijo-Guibourg (1980) y Ross (1971).

Para ilustrar acerca de estos problemas, comenzaremos por dos muestras significativas de lo que podemos llamar la respuesta negativa: las debidas a Della Echave, María Eugenia Urquijo y Ricardo Guibourg, por una parte y a Alf Ross, por otra. El planteamiento de Echave-Urquijo-Guibourg afecta más bien a la primera pregunta; el de Alf Ross, a la segunda.

«Supongamos que hubo entre los charrúas un grupo que vivía de la caza y de la pesca sin sujeción a normas ni autoridades de ninguna clase. Un día, al ver que otras tribus obtenían mejor sus objetivos gracias a la organización de que se habían dotado, decidieron elegir un cacique para que los mandase. La elección recayó en Toro Sentado que, a diferencia de su homónimo piel roja, era un indio pacífico y poco dado a interferir en la vida de sus congéneres. Toro Sentado reunió entonces a la tribu, y dictó su primera norma: «A partir de hoy -dijo- estará permitido cazar los martes y los jueves». Janquel, 
un indígena con dotes innatas de leguleyo, intentó una interpretación a contrario: «¿Eso quiere decir que no podemos cazar los demás días?» «De ninguna manera, -se apresuró a aclarar el benévolo cacique- yo permito cazar los martes y los jueves, pero no digo nada sobre el resto de la semana». Janquel quedó desconcertado, pero Onín, tribeño proclive a las reflexiones éticas, insistió: «¿Tal vez eso implica una promesa de no prohibir en el futuro las cacerías de martes y jueves?». «Tampoco; -repuso Toro Sentado- no me agrada imponer prohibiciones a mi tribu, pero me reservo la posibilidad de cambiar de idea. ¿Qué gobernante no lo hace?» Los aborígenes se miraron unos a otros, y empezaron a dispersarse en silencio: no podían evitar el sentimiento de que la elección del jefe había resultado, al menos hasta ese momento, completamente inútil. Toda la vida habían cazado y pescado como les venía en gana, sin consultar el calendario; y ahora, luego de sancionada la primera ley de su tribu, las cosas seguirían exactamente igual mientras a Toro Sentado no se le ocurriera prohibir algo» (Echave-Urquijo-Guibourg, 1980, págs. 155-156).

Esta historieta muestra muy bien el problema de la irrelevancia pragmática de las normas permisivas. Una norma de obligación constituye una razón para realizar la acción en ella mencionada; una norma prohibitiva constituye una razón para omitir la misma acción. Una norma permisiva, en cambio, no constituye ninguna razón, ni para realizar la acción, ni para omitirla. Tampoco puede operar como criterio de valoración de las acciones realizadas, pues no es posible -por razones lógicas- actuar de forma no correspondiente a la misma. ¿Qué diferencia hay, entonces, entre una situación en la que hay una norma que permite y otra situación en la que no hay norma?

Está muy extendida, sin embargo, la intuición de que no es lo mismo tener un permiso para hacer algo en un determinado caso que el que no haya una norma referida a ese caso. Quizá la razón de esta impresión intuitiva se halle en que los enunciados permisivos sólo aparentemente sean irrelevantes, sólo aparentemente dejen el mundo tal como estaba pues, de hecho, cuando se concede un permiso quizá se esté haciendo algo distinto de lo que expresamente se dice. Tal es la posición de Alf Ross.

«Que me digan lo que me está permitido no me suministra ninguna guía para mi conducta, a menos que el permiso constituya la excepción a una norma de obligación (la cual puede ser tal vez la máxima general de que lo que no está permitido está prohibido). Las normas de permiso tienen la función normativa 
de indicar, dentro de un sistema, cuáles son las excepciones a las normas de obligación del sistema» (Ross, 1971, pág. 114). «Nunca he oído de ninguna ley que se apruebe con el propósito de declarar una nueva forma de conducta (por ejemplo, escuchar la radio) permitida. Si un legislador no encuentra razón para interferir produciendo una prescripción obligatoria (mandato o prohibición) simplemente guarda silencio. No conozco ninguna regla jurídica permisiva que no sea lógicamente una excepción modificativa de una prohibición $\mathrm{y}$, por tanto, interpretable como la negación de una obligación» (id., págs. 115-116).

$\mathrm{Y}$, respecto a la idea de von Wright -sobre la que volveremos en seguida- de entender «las garantías constitucionales de las libertades del ciudadano» como promesas de no interferencia por parte del legislador, dice lo siguiente:

«La idea de una promesa hecha por el legislador al ciudadano, y que cree una obligación moral para el legislador, no es más que un producto de la imaginación, y hace tiempo que fue abandonada por la teoría jurídica. La garantía constitucional de ciertas libertades no tiene nada que ver con promesas, sino que es una restricción del poder del legislador, una incompetencia que corresponde a una inmunidad por parte del ciudadano. El legislador no promete no usar un poder que posee, sino que más bien su poder (o competencia) está definido de tal modo que no puede jurídicamente interferir con las libertades garantizadas. Cualquier acto legislativo al efecto sería inconstitucional y, por tanto, nulo» (id., pág. 117).

Este planteamiento merece un examen algo detallado al menos en dos vertientes. La primera es que, aun si resultara aceptable entender las garantías constitucionales de ciertas libertades como espacios de incompetencia del legislador, ello sólo podría valer para los casos de constituciones rígidas, pero no para los supuestos de constituciones flexibles. La segunda es que el propio entendimiento de las garantías constitucionales como espacios de incompetencia del legislador resulta -por razones que ya explicamos en Atienza-Ruiz Manero (1994) y que aquí retomaremos- claramente inconvincente. Veamos una y otra cosa.

Empecemos por los supuestos de constituciones flexibles, entendiendo por tales aquellas que, de acuerdo con sus propios términos, «pueden ser modificadas por el órgano legislativo ordinario mediante el procedimiento ordinario de formación de las leyes» (Guastini, 
1993, pág. 72). En tales supuestos, la autoridad normativa de la que dimana la constitución no está situada por encima del legislador ordinario, sino que es el mismo legislador ordinario. En tal caso, el constituyente no puede ni conferir el poder normativo de legislar ni delimitar espacios sustraídos a ese poder normativo: pues las relaciones entre constitución y ley se gobiernan, simplemente, en base al principio de lex posterior: una ley posterior que introdujera, por ejemplo, normas prohibitivas donde la constitución establecía permisiones no sería en absoluto una ley inconstitucional, sino que supondría un cambio normativo perfectamente regular.

La virtualidad de la idea de las garantías constitucionales de ciertas libertades como espacios de incompetencia del legislador ordinario parece limitarse, pues, a aquellos supuestos en los cuales la autoridad constituyente es una autoridad distinta y superior a la del legislador ordinario: a los supuestos, pues, de constituciones rígidas. Pero aun aquí la idea resulta inconvincente, por lo siguiente: que una norma sea jurídicamente «nula» puede significar dos cosas radicalmente distintas: puede significar, en primer lugar, que dicha norma no es reconocida por el ordenamiento jurídico como tal normal, esto es, que, desde la perspectiva del ordenamiento, sencillamente no existe como tal; puede significar, en segundo lugar, que el ordenamiento, reconociéndola como tal norma, impone a un determinado órgano el deber de anularla. Pensemos, por ejemplo, en una «ley», de contenido perfectamente constitucional, dictada por un particular: dicha «ley» es «inconstitucional»o «nula» en el sentido de que no es reconocida por el ordenamiento jurídico como tal «ley»; dicha «ley», desde la perspectiva del ordenamiento, sencillamente no existe. O pensemos en una ley aprobada por la mayoría parlamentaria exigida por la Constitución, pero cuyo contenido entre en conflicto con normas constitucionales: porque no respete, por ejemplo, permisiones a los ciudadanos concedidas por la Constitución. La situación es aquí radicalmente distinta: dicha ley es reconocida por el ordenamiento como tal, si bien, bajo la condición de que alguien legitimado para ello impugne su constitucionalidad ante el Tribunal Constitucional, éste tiene el deber de anularla, anulación que conlleva una evidente carga de reproche para el legislador. Cabría decir que, en el primer supuesto, el particular, aun siendo respetuoso con las normas constitucionales que imponen prohibiciones referidas al contenido posible de las leyes, sencillamente no ha usado con éxito (ni podría hacerlo) la norma constitucional que confiere el poder para legislar al Parlamento, mientras que en el segundo, el Parlamento ha usado esa norma con éxito y ha producido por ello el cambio normativo pretendido (el dictado de la ley en cuestión), si bien, al haber vulnerado prohibiciones referidas al ejercicio de dicho poder normativo, el 
Tribunal Constitucional tiene el deber de anular su resultado. Esto es: las garantías constitucionales de ciertos derechos y libertades no implican espacios de incompetencia del legislador ordinario (pues si tal fuera el caso la ley de contenido inconstitucional dictada por el parlamento sencillamente no existiría como tal, como no existe la ley, de contenido constitucional o inconstitucional, dictada por el particular), sino prohibiciones de ejercer esa competencia para producir leyes con determinado contenido.

Esta conclusión, en todo caso, aunque corrija a Ross, viene a avalar su tesis central: a saber, que no hay normas puramente permisivas, que el permiso no constituye una modalidad independiente, sino la excepción a (o derogación de) normas de mandato (de obligación o prohibición) o la formulación indirecta (esto es, para sujetos distintos de sus destinatarios explícitos, para las autoridades normativas subordinadas) de normas de mandato (de obligación o prohibición).

\section{La propuesta de von Wright: las normas permisivas como promesas}

La propuesta de von Wright de entender las permisiones como promesas por parte de su edictor merece más atención que la que podría sugerir el exabrupto de Ross que antes hemos citado. La concepción de las permisiones como promesas es sólo el término final del cuidadoso examen de los permisos (o, más exactamente, de las «prescripciones permisivas») llevado a cabo en Norma y acción (von Wright, 1979), texto al que limitaremos nuestra atención ${ }^{1}$.

En Norma y acción von Wright examina las dos vías, o formas, en que «se ha intentado negar el status independiente de los permisos. Una es considerar los permisos como simple ausencia o no existencia de las prohibiciones «correspondientes». La otra es considerar los permisos como una especie peculiar de prohibiciones; a saber, prohibiciones de interferir la libertad de un agente en un determina do respecto» (pág. 101). El examen de la primera de estas dos vías conduce a von Wright a formular la distinción entre permiso débil y fuerte; mientras que el examen de la segunda le conduce a caracterizar las «prescripciones permisivas» como promesas. Veamos una y otra cosa.

Respecto de la identificación sin más entre permiso de hacer una determinada cosa y ausencia de prohibición de hacer dicha cosa von

\footnotetext{
${ }^{1}$ Sobre los meandros argumentativos y las diversas tomas de posición que a lo largo de su obra ha venido adoptando von Wright sobre los permisos, cfr. Daniel González Lagier ( 1994).
} 
Wright opina que tal opinión es «un serio error», por la siguiente razón:

«No es posible hacer un inventario de todos los actos genéricos concebibles.

Nuevas especies de acto hacen su aparición a medida que se van desarrollando los talentos humanos y van cambiando las instituciones y las formas de vida. Un hombre no podría emborracharse antes de haberse descubierto cómo destilar el alcohol. En una sociedad promiscua no existe la posibilidad de cometer adulterio. Según se van originando las nuevas especies de acto, las autoridades de las normas pueden sentir la necesidad de considerar si ordenarlas o permitirlas o prohibirlas a los sujetos. (...) Por eso es razonable, dada una autoridad de normas, dividir los actos humanos en dos grupos principales: a saber, actos que han sido y actos que no han sido (todavía) sometidos a norma por esta autoridad. De los actos que han sido sometidos a norma, algunos son permitidos, otros prohibidos, otros mandados. Aquellos actos que no han sido sometidos a norma son ipso facto no prohibidos. Si un agente hace tal acto, el legislador no puede acusarle de violar la ley. En este sentido, tal acto puede decirse que está «permitido». Si aceptamos esta división de los actos en dos grupos principales -relativos a una autoridad de normas dada- y si decidimos llamar a los actos permitidos simplemente en virtud del hecho de que no están prohibidos, entonces será sensato distinguir entre dos especies de permiso. A unos les llamaré permisos fuertes, a los otros débiles, respectivamente. Un acto se dirá que está permitido en el sentido fuerte, si no está prohibido, pero está sometido a norma. Los actos que están permitidos en el sentido fuerte, lo están también en el sentido débil, pero no necesariamente viceversa. Hablando en términos generales, un acto está permitido en el sentido fuerte si la autoridad ha considerado su status normativo y decide permitirlo (pág. 101).

Aceptando la distinción así trazada ${ }^{2}$ entre actos permitidos en el sentido débil y actos permitidos en el sentido fuerte, se plantean, sin embargo, estas tres preguntas: (1) La introducción de una norma que

${ }^{2}$ A propósito de este mismo pasaje de von Wright, Alchourrón y Bulygin han puesto de relieve que en él se encuentran dos definiciones distintas de permiso fuerte: (i) un acto está permitido en el sentido fuerte «si no está prohibido, pero está sometido a norma»; (ii) un acto está permitido en el sentido fuerte «si la autoridad ha considerado su status normativo y decide permitirlo». Comentan estos mismos 
permita el acto $\mathrm{X}$, ¿cambia en algo el status del acto $\mathrm{X}$, antes no sometido a norma? Von Wright -como acabamos de ver- dice que si un agente hace (o añadamos, omite) un acto permitido en el sentido débil, «el legislador no puede acusarle de violar la ley». Pero la situación es la misma si hace (u omite) una acción cuya realización y omisión se encuentren permitidas en el sentido fuerte, por la simple razón de que los permisos no pueden ser cumplidos o incumplidos; (2) La introducción de la norma permisiva respecto del acto $\mathrm{X}$ ¿cambia el status de otros actos distintos del acto X, pero relacionados con él, esto es, de actos de impedir o de sancionar la realización de X?; (3) Este cambio del status de actos distintos de aquel sobre el que expresamente versa la norma permisiva ¿implica algo más que la prohibición de impedir o de sancionar esos actos? Si la respuesta a la primera pregunta fuera negativa, la posible relevancia de las normas permisivas habría que encontrarla en relación con actos distintos de aquel sobre el que expresamente versan. Y si la respuesta a la tercera pregunta fuera, asimismo, negativa, las supuestas normas permisivas no serían más que una formulación indirecta de normas prohibitivas. Pero para examinar cuál es la respuesta de von Wright a estas preguntas, antes hemos de ver cómo trata la segunda vía, antes indicada, de negar status independiente a los permisos, esto es, considerarlos como prohibiciones de interferencia. A este respecto, von Wright señala que «parece posible distinguir entre varias especies de permiso fuerte», que -ordenadas de menor a mayor fuerzaserían el «permiso como tolerancia», el «permiso como derecho» y el «permiso como habilitación». Veámoslo:

«Al permitir un acto la autoridad puede estar meramente declarando que va a tolerarlo. A la autoridad «no le interesa» si el sujeto hace el acto o no. La autoridad está determinada a no

autores lo siguiente: «La definición(ii) es aparentemente una explicación complementaria de (i). pero de hecho (i) y (ii) no son equivalentes y, en consecuencia, surge la pregunta de cuál de las dos ha de ser considerada como la definición del «permiso fuerte». En efecto, (i) requiere dos condiciones: (a) un acto no ha de ser prohibido y (b) debe estar "sometido a norma», esto es, debe ser o bien permitido o bien obligatorio. En cambio (ii) expresa una sola condición: el acto debe ser (expresa o implícitamente) permitido. Esta segunda condición es idéntica a (b)» («Permisos y normas permisivas», en Alchourrón-Bulygin, 1991, pág. 217). Es obvio que la definición (i) elimina la posibilidad de permisos fuertes que sean antinómicos con normas prohibitivas y que esta eliminación carece de justificación. Es más, parece que una diferencia importante entre permisos fuertes y débiles reside en que los primeros, al depender de una norma permisiva, pueden dar lugar a contradicciones en el sistema (entre la norma permisiva y una eventual norma prohibitiva) lo que, naturalmente, no puede ocurrir en el caso de los permisos débiles (puesto que éstos se definen como la mera ausencia de norma). 
interferir la conducta del sujeto en lo que a este acto se refiere, pero no se compromete a proteger al sujeto de posibles interferencias de su conducta por parte de otros agentes. Todo permiso (fuerte) es, como mínimo, un tolerar, pero puede ser más que esto. Si un permiso de hacer algo se combina con una prohibición de obstaculizar o impedir al titular del permiso de hacer dicha cosa, entonces diremos que el sujeto de la norma permisiva tiene un derecho en relación con los sujetos de la prohibición. Al conceder un derecho a algunos sujetos, la autoridad declara que tolera un determinado acto (o abstención) y que no tolera otros actos determinados. (...) Debemos distinguir entre no hacer que un acto sea imposible de ejecutar para algunos y hacer un acto posible. Esto último se llama también habilitar (a alguien para algo). Es la noción más fuerte. De habilitar se sigue no-obstaculizar, pero no-obstaculizar no equivale necesariamente a habilitar. Si un permiso de hacer alguna cosa se combina con un mandato de habilitar al titular del permiso a hacer la cosa permitida, entonces diremos que el sujeto de la norma permitida tiene una acción [claim, en el original inglés] frente a los sujetos del mandato. Se comprende que toda acción en este sentido es también un derecho, pero no a la inversa» (págs. 103-104).

Un «permiso como derecho» es un «permiso como tolerancia» más una prohibición de obstaculizar o impedir la realización del acto permitido; un «permiso como habilitación» es un «permiso como derecho» más un mandato de posibilitar la realización del acto permitido. Lo que añaden los «permisos como derechos» y los «permisos como habilitaciones» a los «permisos como tolerancias» son, respectivamente, prohibiciones y obligaciones relativas a la conducta de terceros. Como dice el propio von Wright, «las características específicas [de estas dos últimas especies de permiso fuerte] pueden ser explicadas en términos de prohibiciones y/o mandatos». Y de ello -añade asimismo von Wright- «se desprende que si hay un elemento característico de los permisos que no es reducible a los otros caracteres normativos, este elemento es idéntico a lo que llamamos tolerancia» (pág. 105). Por lo tanto, «para ver si un permiso es un carácter irreductible de las normas, o no, debemos examinar la noción de tolerancia». Una declaración de tolerancia puede ser, bien una declaración de intenciones -y entonces no expresa norma alguna, pues «una declaración de intenciones no es un concepto normativo en absoluto»- bien una promesa -y entonces «la pregunta de si un permiso es definible en términos de los otros caracteres de las normas sería reducible a la pregunta de si el carácter normativo de una promesa (o, por lo menos, de una promesa de no-interferencia) puede expresarse en 
términos de «debe»y «tiene que no»« (pág. 105). A juicio de von Wright, «que la contestación a la última pregunta debe ser afirmativa es algo que probablemente todos admitiremos sin dificultad» (id.). Por ello, aunque este autor finalice su tratamiento de los permisos diciendo que «sobre la cuestión de si un permiso es o no un carácter independiente de la norma, no tomaré aquí una posición definida», parece que de su análisis cabe concluir la negativa, a saber, que aquello que en los permisos no cabe reducir a prohibiciones o mandatos a terceros es reductible a autoprohibiciones de la edictora.

Ello no obstante, esta última noción es, a juicio de von Wright, problemática por lo siguiente: «si se conciben los permisos como promesas, los permisos serían prescripciones auto-reflexivas, es decir, auto-prohibiciones». Y las prescripciones «requieren una autoridad y un sujeto», autoridad y sujeto que en el caso de los permisos como tolerancias se identifican. Que tal cosa sea posible, que pueda haber prescripciones auto-reflexivas es, a juicio de von Wright, una cuestión debatible y, por ello, «si creemos que tales prescripciones no pueden existir, tendremos que llegar a la conclusión de que los permisos no son prescripciones» (pág. 106). Ello, a juicio de von Wright, conduce a considerar los permisos como normas de tipo moral, porque «el que las promesas deben mantenerse normalmente se consideraría como una norma típicamente moral, y la obligación de hacer esto o aquello porque uno ha prometido hacerlo se tomaría como una obligación moral» (pág. 106).

Esta última consideración resulta, sin duda, inmediatamente discutible. Y ello no sólo porque, si «se deben cumplir las promesas» es una norma moral, también lo es en última instancia «se deben cumplir las prescripciones de la autoridad», sino también por razones más internas al Derecho. Pues bien puede ser que la noción de «autoprescripción» sea problemática, pero desde luego la noción de «obligación de creación voluntaria», como consecuencia de promesas, no parece ser problemática en absoluto, pues sobre ella reposan instituciones tan incontrovertidamente jurídicas como los contratos y también los negocios jurídicos unilaterales en los que -al no haber intercambio de promesas, sino ir ésta en una sola dirección- la situación sería sustancialmente la misma que en los permisos como tolerancias tal como los presenta von Wright. Que la autoridad cree una obligación para sí misma no nos parece que genere ningún problema especial de teoría del Derecho.

Nos parece, sin embargo, que sí valdría la pena cerrar este examen del tratamiento de los permisos por parte de von Wright con un par de observaciones. La primera de ellas sería la siguiente: la concepción de los permisos como promesas de no interferencia conduce, pese a las cautelas finales de von Wright, a negar que el permiso sea 
un carácter independiente de las normas: no sería, en lo que no es reductible a prohibiciones a terceros, mas que una autoprohibición de la autoridad. La segunda acotación que nos parece de interés es ésta: la concepción de los permisos como promesas de no interferencia (y, por consiguiente, como auto-prohibiciones) parece especialmente adecuada para los permisos que se dictan en contextos más «informales», o menos institucionalizados, que el jurídico. Por ejemplo, si un padre le dice a su hijo que tiene permiso para bajar al jardín no parece difícil concordar en que el padre adquiere la obligación de no castigarle por ello en caso de que baje al jardín. Sin embargo, en contextos jurídicos su sentido parece bastante más limitado. El constituyente no se prohíbe nunca únicamente a sí mismo interferir con, pongamos por caso, la libertad de expresión. De hecho, solo habría autoprohibición si se tratara de una Constitución que prohibiera su propia reforma en este punto (lo cual es mas bien raro y da lugar a problemas que quedan muy lejos de los abordados aquí); pero también en este caso habría prohibición de interferencia para alguien distinto de él mismo: esto es, principalmente para el legislador ordinario, que es el destinatario usual más importante de este tipo de prohibiciones constitucionales. Otro tanto ocurre cuando el legislador ordinario permite cualquier otra cosa: las prohibiciones de no interferencia con la conducta permitida no van dirigidas a él mismo (el principio de lex posterior parece, en el terreno legislativo, prácticamente universal), sino a los órganos ejecutivos y judiciales $\mathrm{y}$, eventualmente, también a la gente en general. Por ello parece tener razón Ross cuando afirma, respecto de los permisos como tolerancias, que «no sé de ningún acto legislativo que diga tal cosa» (id., pág. 116).

En definitiva, bien se parta de los permisos como ausencia de prohibición o bien como prohibición de interferencia, la conclusión a que se llega, tras el análisis de la obra de von Wright, es que ambas vías conducen, en efecto, a negar a los permisos status independiente.

\section{Permisos débiles y permisos fuertes en Alchourrón y Bulygin}

De entre todas las obras importantes de la teoría del Derecho contemporánea quizá en ninguna como en la de Alchourrón y Bulygin se encuentre tan enfatizada la importancia de la distinción entre permisos fuertes y débiles ${ }^{3}$. Como es bien sabido, esta distinción

${ }^{3}$ Sobre esta distinción ha escrito recientemente Rafael Hernández Marín (1993), formulando algunas críticas respecto a la simbolización utilizada por los autores argentinos, las definiciones de permiso fuerte y débil y las relaciones entre ambos tipos de permiso que, sin embargo, no afectan a la línea argumentativa que aquí se desarrolla. 
constituye uno de los ejes nucleares de Normative Systems (1971; trad. cast. 1974) -el trabajo con el que estos autores, por decirlo con palabras de von Wright, «pasaron al escenario internacional»- y ocupa también un primer plano en trabajos posteriores como «La concepción expresiva de las normas» (1981), «Permisos y normas permisivas» (1984) o «Libertad y autoridad normativa» (1985) [recogidos todos ellos en Alchourrón-Bulygin, 1991]. De todos ellos, «Permisos y normas permisivas» parece ser la elaboración por ahora más completa de sus posiciones al respecto. A continuación, trataremos de exponer con fidelidad lo que nos parecen las tesis básicas de estos autores, advirtiendo ya que, a nuestro juicio, y pese a su insistencia en contrario, de ellas se deriva la prescindibilidad de las categorías de «permiso prescriptivo», «permiso fuerte» y «norma permisiva». Veámoslo:

(1 ) La primera de estas tesis se refiere a los conceptos de permisión. Según Alchourrón y Bulygin, debemos distinguir tres conceptos de permisión: el concepto prescriptivo de permisión más los conceptos descriptivos de permisión fuerte y permisión débil:

«Cuando el término «permitido» figura en una norma expresa el concepto prescriptivo de permisión. Pero cuando el mismo término figura en una proposición normativa es ambiguo: cuando se dice que un estado de cosas $p$ está permitido en un conjunto de normas, esto puede significar dos cosas diferentes; o bien que existe una norma (en $\alpha$ ) que permite $p$, bien que $p$ no está prohibido en $\alpha$. Por lo tanto, hay dos conceptos de permisión descriptiva: permiso fuerte y permiso débil» («Permisos y normas permisivas», en Alchourrón-Bulygin, 1991, pág. 218).

(2) A diferencia de lo que ocurre en sistemas normativos completos y coherentes, en los que la distinción entre permisos débiles y fuertes «se esfuma», pues «ambos conceptos se superponen» (ibíd, pág. 220), la distinción entre permisos fuertes y débiles tiene particular relevancia en el contexto de sistemas normativos incompletos (en los que hay conductas permitidas en el sentido débil que no lo están también en el sentido fuerte) o incoherentes (en los que hay conductas permitidas en el sentido fuerte que no lo están en el sentido débil, al formar parte de los mismos una norma que las prohíbe) (ibíd., pág. 220).

Hasta aquí, las tesis de Alchourrón y Bulygin nos parecen inobjetables. Que una determinada conducta pueda estar simultáneamente permitida en el sentido fuerte y prohibida por parte de dos normas distintas del mismo sistema equivale a decir que los sistemas normativos 
pueden contener antinomias, lo cual es, a nuestro juicio, indiscutible. Pero esto, por sí solo, no es argumento suficiente para considerar lo que ellos llaman permiso prescriptivo como un carácter independiente de las normas, pues esa situación también se podría describir -sin necesidad de hacer referencia a permisos- como una antinomia entre dos normas, una de las cuales prohíbe una determinada conducta en un determinado caso, mientras que la otra niega esta prohibición (esto es, tendría la formulación «no prohibido $p$ en el caso $q »^{4}$ ). Para poder considerar al permiso prescriptivo como un carácter independiente de las normas sería preciso demostrar (1) que cuando una conducta está cubierta por una permisión prescriptiva (esto es, por una norma permisiva, lo que nos permite decir, en el nivel de las proposiciones normativas, que esta conducta está permitida en el sentido fuerte) el status normativo de esta conducta es distinto de cuando está permitida simplemente en el sentido débil y (2) que la alteración del sistema que se produce mediante la introducción de una norma permisiva es algo distinto tanto de la negación o cancelación de prohibiciones como de la introducción, mediante una formulación indirecta, de prohibiciones para conductas distintas, aunque relacionadas con la conducta mencionada por la norma permisiva (esto es, de conductas consistentes en prohibir, impedir o sancionar la conducta mencionada por la norma permisiva). Como escriben ellos mismos, la cuestión crucial está «contenida en la siguiente pregunta: ¿cuál es, después de todo, la diferencia práctica entre el permiso fuerte y el permiso débil, es decir, entre acciones permitidas y acciones simplemente no prohibidas?» (ibíd., pág. 235).

(3) Pues bien: con arreglo a los propios Alchourrón y Bulygin (aunque probablemente no de acuerdo con sus deseos), la «diferencia práctica» entre permiso débil y fuerte, esto es, la alteración producida por la introducción en el sistema de una norma permisiva, puede explicarse por completo en términos bien de negación o cancelación de prohibiciones, bien de formulación indirecta de prohibiciones.

(3.1) Supongamos, reformulando ligeramente un ejemplo de los mismos Alchourrón y Bulygin (1974, pág. 224), las dos normas siguientes:

${ }^{4}$ Se dirá que «no prohibido $p$ en el caso $q$ » es una extraña formulación de norma, y así es. Pero: (1) «extraña» significa aquí únicamente «chocante», esto es, ajena a los usos estilísticos habituales, y no «carente de sentido» o «portadora de algún defecto lógico»; (2) los propios Alchourrón y Bulygin nos ofrecen ejemplos de formulaciones de normas muy semejantes, como por ejemplo, cuando hablan de «una norma de la forma 'No obligatorio $p$ en el caso $q$ » o de una norma expresada por -Op, o por -Ph-p (Alchourrón-Bulygin, 1974, págs. 220-221). 
$\mathrm{N} 1$ : Si se dan las circunstancias A y B, prohibido $p$.

$\mathrm{N} 2$ : Si se dan las circunstancias no-A y no-B, permitido $p$.

Imaginemos ahora, prosiguiendo con el ejemplo, que nos enfrentamos a un estado de cosas tal que se dan las circunstancias A y no-B. De acuerdo con Alchourrón y Bulygin, en una situación como la descrita, el intérprete no podría encontrar una solución satisfactoria, porque «el argumentum e contrario permite inferir dos soluciones incompatibles, según cuál de las dos normas se adopte como premisa». Por eso, la solución al problema tendría que venir dada por la introducción de una tercera norma

N3: Si se dan las circunstancias A y no-B, permitido $p$.

la cual posibilita solucionar el caso sin necesidad de decidir previamente si hemos de adoptar como premisa de un argumentum e contrario N1 o N2. Ahora bien, como es obvio, esa solución podría alcanzarse también ( $\sin$ necesidad de introducir una norma permisiva) si en vez de N1 nos encontráramos con:

N1': Sólo si se dan conjuntamente las circunstancias A y B, prohibido $p$.

Esto es: N3 no hace otra cosa más que limitar (precisándolo para un caso no previsto) el alcance de la norma prohibitiva N1. N3 niega que la prohibición establecida en N1 se extienda al caso que presente las circunstancias A y no-B. Si N1 se sustituye por N1', tanto N3, como también N2, resultan superfluas.

(3.2) Una función importante de los enunciados permisivos es la de derogar normas prohibitivas.

«Una prohibición no puede ser levantada por medio de otra prohibición. Para cancelar o derogar una norma imperativa tenemos que realizar otro tipo de acto normativo, que es radicalmente distinto del acto de prohibir. Las normas permisivas a menudo (si no siempre) realizan la importante función normativa de derogar prohibiciones» («Permisos y normas permisivas», en Alchourrón-Bulygin, 1991, pág. 235).

Pero el tipo de acto normativo necesario para derogar una norma prohibitiva no necesariamente debe ser entendido como un acto de permitir. Puede entenderse simplemente como un acto de derogar (esto es, de cancelar una prohibición). Si entendiéndolo así explicamos lo mismo, 
esta alternativa resulta preferible en virtud del principio de economía, pues no necesitamos introducir el permiso como un carácter independiente de las normas. Y esto es lo que Alchourrón y Bulygin vienen a admitir en «La concepción expresiva de las normas». Bajo el epígrafe «Permisión», se plantean de qué manera una teoría expresivista de las normas puede dar cuenta de los actos que consisten en otorgar un permiso para realizar la acción $p$ e indican que

«parece haber dos vías para enfrentar esta dificultad. (i) Una vía consiste en describir ese acto como un acto de levantar una prohibición, es decir, como una derogación de la prohibición de $p$ (ii). Una vía alternativa sería aceptar un nuevo tipo de acto normativo, el acto de permitir u otorgar un permiso. Si se acepta esta segunda vía, entonces ha de ser aceptado también que hay dos tipos de normas (en el sentido en que un expresivista usa el término «norma»), normas imperativas y normas permisivas (...). Uno se siente tentado a formular la pregunta: ¿son estos dos análisis realmente distintos? Cuál es la diferencia, si hay alguna, entre promulgar una permisión y derogar una prohibición? (...) Uno tiene la impresión de que los dos análisis son sustancialmente equivalentes en el sentido de que representan dos distintas descripciones de la misma situación. Si esto fuera así, sería un resultado más bien sorprendente, pues mostraría la fecundidad del concepto de derogación y su importancia para la teoría de las normas. El concepto de norma permisiva resultaría teóricamente superfluo: se podría prescindir de él. Esto justificaría la posición de aquellos expresivistas que sólo aceptan normas imperativas, con la condición de que acepten la noción de derogación»(Alchourrón-Bulygin, 1991, págs. 146-149).

(3.3) Otra función importante de las normas permisivas es regular el ejercicio de los poderes normativos de autoridades de rango inferior al de aquélla que dicta la norma permisiva. Escriben así en «Permisos y normas permisivas», a propósito de la historieta antes recordada de Echave-Urquijo-Guibourg:

«Supongamos que un día Toro Sentado decide nombrar un ministro. El ministro está autorizado para dictar nuevas normas para regular la conducta de la gente y para derogarlas, pero carece de competencia para derogar las normas dictadas por Toro Sentado mismo. En tal caso el permiso dado por Toro Sentado de cazar los martes y los jueves funciona como una limitación de la competencia de su ministro: el ministro 
no puede derogar esas normas y de este modo no puede prohibir la caza en esos días, aunque pueda prohibir la caza en los demás días de la semana. De tal manera, estos permisos pueden ser interpretados como un rechazo anticipado de las prohibiciones correspondientes» (Alchourrón-Bulygin, 1991, págs. 236-237; en términos similares en «Libertad y autoridad normativa», Alchourrón-Bulygin, 1991, págs. $244 \mathrm{ss}$.).

Como se habrá podido observar, en este texto Alchourrón y Bulygin entienden que las prohibiciones de ejercicio de una determinada competencia forman parte de la norma de competencia misma. A nuestro modo de ver -por las razones que antes apuntábamos a propósito de Ross-, es preferible ver estas prohibiciones como el contenido de normas regulativas relativas al ejercicio de la competencia, normas regulativas que son distintas de la norma de competencia misma. Pero esto es algo que en el presente contexto no tiene demasiada importancia por dos razones: En primer lugar, porque la distinción entre la norma de competencia y las normas regulativas que guían su ejercicio ha sido aceptada con posterioridad por los autores que comentamos; y así, en «Sobre las normas de competencia», escribe Eugenio Bulygin, que «situaciones en las que una persona tiene competencia para realizar cierto tipo de actos y al mismo tiempo le está prohibido hacer uso de esa competencia son relativamente frecuentes» (Alchourrón-Bulygin, 1991, pág. 489). Y, en segundo lugar, porque la cuestión de si las prohibiciones de ejercicio de una competencia forman parte o no de la norma misma de competencia no es esencial para el tema que nos ocupa; lo importante aquí es que, de acuerdo con Alchourrón y Bulygin, los permisos concedidos por autoridades de rango superior no son más, en relación con las autoridades normativas subordinadas, que prohibiciones indirectamente expresadas. Tampoco desde este ángulo hay, por consiguiente, razones para considerar al permiso como un carácter independiente de las normas.

\section{Para un replanteamiento del problema}

\section{Permisos y reglas regulativas de la conducta «natural»}

Hasta aquí hemos examinado lo que creemos más relevante de la teoría del Derecho actual sobre el tema que nos ocupa. Debemos

${ }^{5}$ Hay dos fases en el tratamiento por parte de Alchourrón y Bulygin de las normas de competencia. En una primera fase las entienden como normas permisivas; después pasan a considerarlas como definiciones o reglas conceptuales. Para la crítica de ambas perspectivas véase Atienza-Ruiz Manero, 1994. 
ahora recordar, para tratar de abordarlos directamente, los dos problemas que indicábamos al comienzo de este trabajo. El primero era si la existencia de enunciados permisivos (que facultan a hacer $\mathrm{u}$ omitir una determinada acción, $p$ ) era o no irrelevante, esto es, si cambiaba o no las cosas en relación con una situación en la que en el sistema jurídico en cuestión no existiera ninguna norma que se refiriera a $p$. El segundo problema -que sólo se plantea si la respuesta al primero no es totalmente negativa- era el de determinar cuál pueda ser la relevancia de esos enunciados permisivos y si esa relevancia puede o no expresarse en términos de normas de mandato (de obligación o de prohibición), es decir, sin necesidad de introducir la categoría de las normas permisivas.

El que la respuesta a la primera cuestión no sea enteramente negativa puede aclararse cuando se repara en una cierta ambigüedad que la pregunta en cuestión contiene. Pues, en efecto, decir que en el sistema jurídico $\mathrm{S}$ no existe ninguna norma que se refiera a $p$ puede significar que:

1) $p$ no es una conducta que caiga dentro del ámbito regulado por $\mathrm{S}$; dicho de otra forma, la conducta $p$ es, con respecto a $\mathrm{S}$, indiferente;

2) $p$ es una conducta relevante para el sistema $\mathrm{S}$, pero no hay ninguna norma que se refiera a ella porque:

a) no se ha considerado necesario (por ejemplo, porque no se ha considerado la posibilidad de que fuera interpretativamente sostenible extender a $p$ el alcance de una norma de mandato), o bien

b) no se ha previsto la conducta $p$ :

$\left.b^{\prime}\right)$ por razones subjetivas, esto es, por defecto del legislador.

$b^{\prime \prime) ~ p o r ~ r a z o n e s ~ o b j e t i v a s, ~ e s t o ~ e s, ~ c o n ~ p o s t e r i o r i d a d ~ a l ~ e s t a b l e c i m i e n t o ~ d e ~ l a s ~ n o r m a s ~}$ del sistema $\mathrm{S}$ han surgido nuevas circunstancias -nuevas posibilidades de acción- que el legislador no pudo prever.

Naturalmente, la distinción entre 1 ) y 2) presupone que existen conductas jurídicamente indiferentes, esto es, conductas en las que un determinado sistema jurídico simplemente no está interesado, o no lo está por el momento; el concepto de conducta jurídicamente indiferente es, pues, relativo a un determinado sistema jurídico en un determinado momento temporal. Ciertamente, puede ser problemático fijar los límites que en un determinado momento y en relación con un determinado sistema jurídico tiene lo jurídicamente indiferente; fijar, esto es (por utilizar terminología de Alchourrón y Bulygin -1974-) el Universo de Discurso (el conjunto de situaciones y estados de cosas) y el Universo de Acciones en los que un determinado 
sistema jurídico está interesado. Pero, en todo caso, el concepto de conducta indiferente es claramente pertinente, a nuestro juicio, en relación con subsistemas parciales (con los que normalmente trabajan los juristas) tales como, por ejemplo, el Derecho de familia o el Derecho de la Comunidad Autónoma Valenciana. En estos casos, la fijación del Universo de Discurso y del Universo de Acciones puede presentar zonas de penumbra, pero eso implica también la existencia de zonas de claridad: parece obvio que hay formas de conducta en las que el Derecho de Familia, o el Derecho de la Comunidad Autónoma Valenciana, no está interesado. En relación con el sistema jurídico en su conjunto cabe dudar, sin embargo, de que haya conductas propiamente indiferentes. El hecho de que, como dice Raz (1991, pág. 175), los sistemas jurídicos pretendan autoridad para regular cualquier tipo de conducta -esto es, reclamen para sí una competencia materialmente ilimitada- es un buen argumento en favor de la tesis de la inexistencia (desde el punto de vista del sistema jurídico en su conjunto) de conductas indiferentes: aquí cabría decir que -en virtud de la competencia materialmente ilimitada que los sistemas jurídicos como tales reclaman para sí- todo lo no prohibido está permitido, esto es, regulado jurídicamente.

Ahora bien, con independencia de que se considere o no que se trata de una acción jurídicamente indiferente, lo que no parece que tendría mucho sentido es que, por ejemplo, el rectorado de la Universidad de Alicante dictara una norma permitiendo que los profesores elijan el color de sus pantalones. Si esto ocurriera, los destinatarios pensarían probablemente que se les estaba gastando una broma o bien que algo preocupante había ocurrido con la salud mental de quienes ocupan los órganos rectores de esa universidad. Esa supuesta norma dejaría -desde el punto de vista de la deliberación práctica de sus destinatarios- las cosas exactamente igual que estaban, por la sencilla razón de que antes todos pensaban que elegir el color de la ropa era una cuestión de cada cual, exactamente igual que ahora.

Si se supone -como nos parece que hay que hacer- que una norma debe guiar en algún sentido la conducta de sus destinatarios, eso quiere decir que una norma permisiva sólo puede cumplir esa función -o sea, no ser superflua- si se dicta en un contexto en que se da alguna de las circunstancias aludidas antes en 2), a las que llamaremos C2, o bien una nueva circunstancia, $\mathrm{C} 3$, consistente en que el sistema jurídico $\mathrm{S}$ ha regulado hasta entonces la conducta $p$ mediante una norma de mandato, esto es, estipulando que la conducta en cuestión es obligatoria o prohibida.

El dictado de una norma permisiva en el sistema $\mathrm{S}$, digamos en el tiempo $\mathrm{t} 2$, cambia las cosas con respecto al mismo sistema en el tiempo t1, en alguno de estos dos sentidos: 
1) Si en el tiempo tl se daban las circunstancias $C 2$, entonces el cambio consiste en aclarar -o, si se quiere, fijar- el status normativo de $p$, es decir, al no existir una norma que explícitamente estableciera que $p$ era una conducta facultativa, la nueva norma, al aclarar la situación, da seguridad a los destinatarios y, en ese sentido, bien puede decirse que contribuye a guiar su conducta: el hecho de saber con certeza que un determinado comportamiento es facultativo -esto es, que está libre de restricciones normativas- hará sin duda que muchos empiecen a hacer -o dejen de hacer- lo que en otro caso no harían -o no dejarían de hacer.

2) Si en el tiempo t1 se daban las circunstancias C3, entonces el establecimiento de la norma permisiva en $\mathrm{t} 2$ cambia las cosas en el sentido de que se modifica el estatus deóntico de $p$ : de obligatorio o prohibido pasa a ser facultativo. La relevancia en términos normativos de la nueva norma es cosa obvia: ésta libera a la conducta $p$ de las restricciones normativas que antes gravitaban sobre ella.

La respuesta al segundo problema que planteábamos al inicio de este trabajo es que la «relevancia» de las normas -o de los enunciados- permisivas parece poderse explicar por completo en términos de negación, derogación y excepción de normas de mandato (o de formulación indirecta de las mismas) y, eventualmente, de definiciones. Imaginemos una situación correspondiente a C2. En el sistema hay, en t1, una norma que prohíbe permanecer en la playa en actitud indecorosa y surge la duda de si está comprendido dentro de su alcance el que las mujeres permanezcan en top-less. El dictado en t2 de una norma cuyo tenor fuera «se permite a las mujeres permanecer en top-less en la playa» sería pragmáticamente equivalente al dictado de una disposición definitoria (parcial) de «actitud indecorosa» cuyo tenor fuera «no se entenderá por actitud indecorosa el top-less femenino». Pasemos ahora a una situación tipo C3. El sistema contiene en $\mathrm{t} 1$ una norma por la que se prohíbe el transporte de caballos fuera de la provincia en la que se encuentren. Resulta obvio que el dictado en $\mathrm{t} 2$ de una norma permisiva -«se permite el transporte de caballos fuera de los límites de la provincia en la que se encuentren»- resulta pragmáticamente equivalente al dictado de una disposición derogatoria -«queda derogada la norma que prohibía el transporte de caballos más allá de los límites provinciales». Del mismo modo, el dictado en t2 de una disposición cuyo tenor fuera «se permite el transporte de caballos entre las provincias andaluzas» equivaldría pragmáticamente al dictado de una disposición que exceptuara a las provincias andaluzas de la prohibición establecida en $\mathrm{t} 1$. 


\section{Permisos y ejercicio de poderes normativos}

Los ejemplos de permisos que acabamos de utilizar pertenecen como es fácil darse cuenta, al ámbito de las reglas regulativas de la conducta natural (entendiendo por tal aquella conducta que no consiste en el ejercicio de un poder normativo). Trasladémonos ahora de este contexto a la regulación del ejercicio de poderes normativos. De poderes esto es, conferidos por reglas cuya forma canónica, según hemos sostenido en otro lugar (Atienza-Ruiz Manero, 1994), sería la siguiente: «Si se da el estado de cosas X y Z realiza la acción $\mathrm{Y}$, entonces se produce el resultado institucional (el cambio normativo) R». Sobre una regla de este tipo pueden, a su vez, incidir otras reglas tanto respecto de la acción y como del resultado R. Empecemos por este último.

En una caracterización muy general podemos distinguir entre poderes normativos de ejercicio obligatorio (como, por ejemplo, el poder jurisdiccional: el juez tiene la obligación de producir el resultado institucional «sentencia») y poderes normativos de ejercicio facultativo (como, por ejemplo, los poderes contractuales privados) ${ }^{6}$. Pero esta caracterización resulta excesivamente gruesa, pues el resultado puede ser en parte obligatorio y en parte facultativo. Así,

${ }^{6}$ Puede haber poderes normativos cuyo ejercicio mismo le esté prohibido al titular del poder. E. Bulygin escribe, en un texto ya recordado antes, que «situaciones en que una persona tiene la competencia para realizar cierto tipo de actos y al mismo tiempo le está prohibido hacer uso de esa competencia son relativamente frecuentes. Por ejemplo, de acuerdo a nuestra ley sólo los abogados son competentes para el patrocinio letrado, pero si un abogado es nombrado juez (y para ser juez normalmente se requiere el título de abogado), entonces le está prohibido ejercer la profesión de abogado. Supongamos que un juez firma una demanda como letrado patrocinante: como abogado él es competente para hacerlo y su firma produce todos los efectos legales, pero como es un juez, le está prohibido ejercer la profesión de abogado y por lo tanto al firmar la demanda viola uno de sus deberes y puede ser pasible de una sanción» («Sobre las normas de competencia», en Alchourrón-Bulygin, 1991, pág. 449), Un ejemplo semejante, en el ámbito del Derecho canónico, es el del ejercicio de los poderes normativos propios de los sacerdotes y obispos católicos (poderes sacramentales) por parte de los sacerdotes y obispos afectados por una suspensión a divinis. En todo caso, que el ejercicio mismo del poder normativo correspondiente le esté prohibido al titular del mismo, es una situación más bien rara, pues -fuera de una concepción mágica (sacramental, por ejemplo) de los poderes normartivos- no parece que tenga mucho sentido mantener a alguien como titular de un poder normativo a la vez que se le prohíbe absolutamente su ejercicio. Cuestión distinta -a la que ya antes hacíamos referencia en el texto- es que alguno de los resultados normativos que el titular de un poder normativo puede (en el sentido de que tiene capacidad normativa para) producir sea un resultado normativo prohibido por las normas regulativas que guían el ejercicio de dicho poder (por ejemplo, el dictado de una sentencia ilegal o de una ley inconstitucional). Sobre estos problemas, cfr. Atienza-Ruiz Manero, 1994. 
por ejemplo, de acuerdo con el ordenamiento español el Gobierno tiene la obligación de proponer al Rey el nombramiento del Fiscal General del Estado, pero es limitadamente libre a la hora de escoger la persona a proponer (limitadamente, pues ha de hacerlo «entre juristas españoles de reconocido prestigio, con más de quince años de ejercicio efectivo de su profesión»). De manera que para el Gobierno resulta obligatorio proponer a algún jurista español de reconocido prestigio, etc., para que sea nombrado por el Rey como Fiscal General del Estado, pero es facultativo proponer el nombramiento del jurista español de reconocido prestigio, etc. Garcigómez. También puede ocurrir que el mismo poder normativo sea de ejercicio obligatorio en unos casos y facultativo en otros. Así, por ejemplo, de acuerdo con la legislación española, los administradores de una sociedad son los titulares del poder normativo de convocar la junta general de la misma y realizar esta convocatoria es obligatorio para ellos en determinados casos (dentro de determinados plazos temporales, cuando así lo soliciten socios que representen un determinado porcentaje del capital, etc.) y facultativo en los demás.

Para aclarar el sentido de calificar a un resultado normativo como «facultativo», conviene recordar las diferencias que existen entre una regla de mandato y una regla que confiere poder, en términos de razones para la acción. Utilizaremos, para ello, por una parte, la teoría de Joseph Raz (1991) respecto a las reglas como razones para la acción y, por otra, una traducción de algunos tipos de imperativos kantianos al lenguaje de las razones para la acción.

Las reglas de mandato constituyen, de acuerdo con la teoría de Raz, razones operativas de un tipo especial: son razones protegidas o perentorias para hacer lo que ellas establecen, excluyendo como gula de la conducta el propio juicio acerca de las razones en pro y en contra de ello; si, en lugar de la teoría de Raz, adoptamos la clasificación kantiana de los imperativos y la adaptamos al lenguaje de las razones para la acción, diríamos que se trata de razones categóricas: señalan qué debe hacerse con independencia de cuáles sean los deseos e intereses del sujeto. Por eso, un enunciado permisivo puede verse como la negación de una razón perentoria o categórica: tales enunciados contribuyen a guiar la conducta -hemos dicho- en cuanto que al suprimir o aclarar que no existe esa razón perentoria (para hacer $p$ o para omitir $p$ ) dejan expedito el camino para que sean los deseos e intereses del sujeto los que actúen como razón operativa.

Las reglas que confieren poder inciden sobre la conducta, sin embargo, de manera muy distinta; ellas lo hacen en forma indirecta: señalan de qué forma se puede obtener un determinado fin que consiste en un cierto resultado normativo: no son, pues, dicho en la terminología de Raz- razones operativas, sino razones auxiliares. 
$\mathrm{O}$, vertiendo al lenguaje de las razones para la acción la clasificación kantiana de los imperativos, diríamos que no son razones categóricas, sino hipotéticas. Y aquí lo que ocurre es que el ordenamiento jurídico considera que algunos de esos fines o resultados el sujeto puede quererlos o no -por ejemplo, llegar a ser una persona casada, vender una finca de su propiedad, convocar la junta de accionistas cuando la realización de esa convocatoria no es obligatoria-, mientras que otros son resultados que el sujeto no puede no querer: el juez no puede no querer dictar una sentencia, el Gobierno no puede no querer nombrar fiscal general, etc. Cabría aquí trazar un paralelismo con lo que Kant llamaba, respectivamente, imperativos hipotético-problemáticos e imperativos hipotético-asertóricos y hablar, en consecuencia, de razones hipotético-problemáticas e hipotético-asertóricas. Una regla que confiere poder es siempre una razón hipotética, pues suministra una razón para hacer algo si se da un determinado estado de cosas y siempre y cuando se tenga, a su vez, una razón para lograr un cierto resultado o fin. La razón hipotética es problemática si el tener o no la razón para lograr el resultado se deja librado al titular del poder; y es asertórica si la razón para lograr el resultado se le impone al titular del poder, esto es, escapa de su control (normativo). El que el resultado normativo aparezca entonces regulado como facultativo vendría a ser el «marcador» de que la regla que confiere el poder de que se trate opera como una razón hipotético-problemática. Su función es, pues, la de especificar qué tipo de razón hipotética es la regla que confiere poder en que se integra. Pero, como ya hemos indicado, un resultado normativo puede ser obligatorio en alguno de sus elementos y facultativo en otros o bien puede ser obligatorio en ciertas circunstancias y facultativo en otras. Si un elemento del resultado (por ejemplo, proponer el nombramiento del Fiscal General del Estado y hacerlo entre juristas españoles de reconocido prestigio, etc.) es obligatorio, mientras que otro (nombrar a un jurista determinado) es facultativo, la regla que confiere poder para producir tal resultado constituye una razón hipotético-asertórica por lo que hace al primer elemento e hipotético-problemática por lo que hace al segundo. Si la producción del resultado es obligatoria en unos casos y facultativa en otros, la regla que confiere poder constituirá una razón hipotético-asertórica en los primeros e hipotético-problemática en los segundos.

En relación con las reglas regulativas de la conducta natural, hemos visto antes que las circunstancias en las que tenía sentido el dictado de una norma permisiva eran, o bien (a lo que llamábamos C2) la existencia de una duda acerca de la aplicabilidad o no a la conducta en cuestión de una norma de mandato, o bien (a lo que llamábamos C3) la existencia de una norma de mandato cuya aplicabilidad 
a esa conducta se desea cancelar. ¿Son estas mismas circunstancias las que dotan de sentido al dictado de normas permisivas en el contexto que ahora estamos examinando? Evidentemente, cuando la norma permisiva se dicta simultáneamente a la regla que confiere el poder correspondiente, no tiene sentido hablar en términos de $\mathrm{C} 3$, por la sencilla razón de que la forma de conducta consistente en producir un resultado normativo tiene como condición de posibilidad la regla que confiere el poder normativo correspondiente. Pero, naturalmente, es perfectamente posible que la producción de un cierto resultado normativo se modalice como obligatoria (o como prohibida) al tiempo del dictado de la regla que confiere el poder correspondiente y que posteriormente se desee cancelar o limitar el alcance de esa regla de mandato. Para conseguir tal cosa podría utilizarse -como en el caso de la conducta natural- bien el dictado de una disposición derogatoria, bien el de una disposición permisiva. Por lo que hace a las circunstancias C2, es obvio -por lo anteriormente dicho- que cuando la regla permisiva respecto del ejercicio (o de un elemento del ejercicio) de un poder normativo se dicta simultáneamente a la regla que confiere el poder de que se trate, el dictado de la primera no puede cumplir la función de aclarar una duda preexistente, sino más bien al de impedir ab initio el surgimiento de una duda tal, formulando desde el momento mismo en que se confiere el poder normativo una negación de la aplicabilidad al ejercicio del mismo (siempre o en ciertas circunstancias, respecto de su integridad o respecto de alguno de sus elementos) de una regla de mandato, esto es, de una razón perentoria.

Pasemos ahora a la acción que la regla que confiere poder vincula con la producción del resultado normativo de que se trate, esto es, al elemento $\mathrm{Y}$ de nuestra «forma canónica». Hablar de «acción» en este contexto supone, evidentemente, una cierta simplificación. Conviene, por ello, precisar lo siguiente: las reglas que confieren poder no suelen vincular la producción del resultado normativo con una única acción sino, bien con una determinada conjunción de acciones (con un curso de acción), bien con una disyunción de cursos de acción, bien con alguna combinación de ambas ${ }^{7}$. En este contexto, decir que un determinado curso de acción (que una determinada

\footnotetext{
${ }^{7}$ Naturalmente, todo ello puede describirse como una acción unitaria atendiendo al resultado: por ejemplo, al resultado «haber contraído matrimonio» corresponde la acción «contraer matrimonio». Pero es obvio que, en la regla que confiere poder, la acción no puede describirse así, pues entonces ésta vendría a decir que si alguien (que reúna ciertos requisitos, tales como estar soltero, ser mayor de determinada edad, etc.) contrae matrimonio, entonces ese alguien ha contraído matrimonio. En la formulación de la regla que confiere poder, la acción ha de describirse de forma independiente del resultado, esto es, como acción natural o como acción
} 
conjunción de acciones) o algún tramo del mismo es obligatorio significa que ha de seguirse necesariamente dicho curso de acción o dicho tramo del mismo para producir el resultado normativo (esto es, que dicho curso de acción o dicho tramo es condición necesaria -y eventualmente suficiente- del resultado), mientras que decir que al sujeto normativo le está permitido elegir entre diversos cursos de acción -o que, dentro de un curso de acción, en tal tramo puede elegir- entre diversos subcursos de acción- significa que seguir alguno de dichos cursos o subcursos de acción es condición necesaria -y eventualmente suficiente- del resultado. «Obligatorio» $\mathrm{y}$ «permitido» no tienen aquí significado deóntico, sino anankástico (o, desde el punto de vista de sus usuarios, técnico): indican, en el primer caso, que el sujeto normativo, para producir el resultado, tiene que seguir un determinado curso de acción y, en el segundo que, para producir el resultado, puede -en sentido no deóntico- elegir entre diversos cursos o subcursos de acción, teniendo que elegir alguno de ellos ${ }^{8}$.

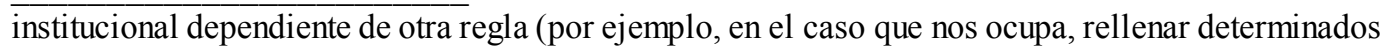
formularios, prometer determinadas cosas ante un juez, etc.). (Hemos tornado en cuenta aquí una sugerencia de Ricardo Caracciolo contenida en su trabajo, aún no publicado, «Dos tipos de poder normativo», en el que critica nuestra concepción de las reglas que confieren poder).

Daniel González Lagier nos sugiere otra manera de expresar lo anterior (que probablemente resulta menos intuitiva), utilizando la distinción de von Wright entre actividad y acción. Diríamos entonces que la regla que confiere poder señala cuál es la actividad (rellenar los formularios, etc.) necesaria (y, en su caso, suficiente) para realizar la acción (que se describiría entonces atendiendo al resultado: contraer matrimonio).

${ }^{8}$ En algunos de sus trabajos (1968 y 1969), von Wright propuso construir la lógica deóntica como un fragmento de la lógica de las condiciones. Así, por ejemplo, la obligación se define en términos de condición necesaria: «Op»» =df «Nc (p, I)», es decir: «que algo debe ser, o debe ser hecho, es establecer que el ser o hacer de esa cosa es una condición necesaria de alguna otra cosa» (1968, pág. 5). La permisión débil (equivalente a «-0-») también permanecería en el ámbito de las condiciones necesarias: sería la negación de que el contradictorio de un determinado estado de cosas (o de una acción) es condición necesaria de I. Y el permiso fuerte se define en términos de condición suficiente: «Pp» $=\mathrm{df}$ «Sc (p. I)», es decir, $p$ está permitido equivale a decir que I) es condición suficiente para alquna otra cosa. «I» es una constante proposicional cuyo contenido no necesita ser especificado, aunque un significado característico en el ámbito de las normas jurídicas, podría ser «innumidad al castigo». Ahora bien, como acertadamente ha señalado González Lagier (1994) «la lógica de las normas basada en la teoría de las condiciones no es en realidad (...) una lógica de los conceptos deónticos, sino más bien una lógica de las nociones de deber y poder técnicos» (pág. 56a). Es decir, esa lógica no sería apta para dar cuenta de las normas deónticas, pero podría tener una aplicación en el contexto de las reglas que confieren poder. En concreto, nos parece que de esta manera se puede dar cuenta de las nociones de «permitido» y «obligatorio» en relación con el elemento «Y» de nuestra «forma canónica» de regla que confiere poder. Cuando el elemento Y se 
Lo dicho hasta ahora permite, nos parece, salir parcialmente al paso del argumento de la irrelevancia práctica de las normas permisivas que planteaban Echave-Urquijo-Guibourg. En la divertida historieta que ellos cuentan su conclusión no es otra sino que «las cosas seguirían exactamente igual mientras a Toro Sentado no se le ocurriera prohibir algo». Pues al elegir a Toro Sentado como cacique, los charrúas sí parecen haber cambiado su universo normativo (antes, en el ejemplo, vacío) mediante la introducción -nos parece- de, al menos, una regla que confiere poder a Toro Sentado para dictar normas vinculantes para el resto de los miembros de la tribu. Y ello, evidentemente sí modifica las expectativas de los miembros de la tribu. Y lo que, por cierto, nos parece extraño es que entre los charrúas no hubiese alguien -digamos, algún Hartín- lo suficientemente despierto como para darse cuenta de que la elección de Toro Sentado sí que cambiaba las cosas y de un par de circunstancias más. En primer lugar, de que esta elección presuponía -frente a la imagen de universo normativo vacío que según el ejemplo los charrúas tenían de sí mismosal menos la existencia de una regla según la cual los charrúas en su conjunto tenían el poder normativo de elegir un cacique (esto es, tenían el poder normativo de conferir a alguien el poder normativo de dictar normas vinculantes y de imponerle o no -como parece ser el caso del ejemplo- obligaciones o prohibiciones relativas al ejercicio de ese poder). En segundo lugar, de que si se confiere a Toro Sentado el poder de dictar normas vinculantes, es preciso determinar qué tiene que hacer Toro Sentado para dictar tales normas o (lo que es lo mismo) qué curso o cursos de acción ha de seguir Toro Sentado para que sus manifestaciones deban ser reconocidas por los charrúas como constitutivas del dictado de una norma -esto es, cuándo la manifestación de Toro Sentado debe ser vista por los charrúas como constitutiva de una razón para la acción- y no como meramente expresivas de un juicio de deber -mediante cuya formulación Toro Sentado expresa la existencia de razones para la acción independientes de su propia manifestación.

toma en bloque, entonces cabe decir que la acción Y es condición necesaria (y suficiente si se le añade $\mathrm{X}$ ) para el resultado $\mathrm{R}$ (R sería aquí la traducción de I). Pero cuando lo que se toma es un fragmento de $\mathrm{Y}$ (digamos, la acción acción $b$, situado entre a y c), entonces decir que b es obligatorio significaría que, dado a, realizar b es condición necesaria y suficiente para c; mientras que b está permitido si realizar b es una condición suficiente para e (y existe al menos otra acción, d, que también es, dado a, condición suficiente para c).

${ }^{9}$ Sobre este punto, en general, cfr. Bayón (1991), págs. 48 ss. 


\section{Permisos y principios. Las libertades constitucionales}

Además de los permisos referidos a la conducta natural y al ejercicio de poderes normativos, existe en el derecho un tercer tipo de enunciados permisivos, las libertades constitucionales, que exige, a nuestro juicio, un tratamiento separado. Como vimos a propósito de Ross, de von Wright y de Alchourrón y Bulygin, puede resultar tentador ver los permisos constitucionales como equivalentes a prohibiciones de interferencia dirigidas al legislador y, en general, a las autoridades subordinadas. En lo que sigue, sostendremos, sin embargo que, si bien es cierto que de los permisos constitucionales se derivan prohibiciones al legislador y, en general, a las autoridades subordinadas, el permiso constitucional se halla, por así decirlo, en un plano justificativo superior y que la fuerza expansiva de los permisos constitucionales no se agota en las correspondientes prohibiciones de interferencia. Partamos también aquí de un ejemplo, constituido por dos disposiciones de la Constitución española:

(a) «Corresponde a los poderes públicos promover las condiciones para que la libertad y la igualdad del individuo y de los grupos en que se integra sean reales y efectivas; remover los obstáculos que impidan o dificulten su plenitud y facilitar la participación de todos los ciudadanos en la vida política, económica, cultural y social» (art. 9.2).

(b) «Se reconocen y protegen los derechos: a) A expresar y difundir libremente los pensamientos, ideas y opiniones mediante la palabra, el escrito o cualquier otro medio de reproducción (...). d) A comunicar o recibir libremente información veraz por cualquier medio de difusión» (art. 20.1).

Se concordará sin dificultad en que el contenido del art. 20.1 puede parafrasearse (al menos parcialmente) de la siguiente forma: «Está permitido expresar o no expresar, difundir o no difundir, cualquier pensamiento, idea, opinión o información».

En un trabajo anterior sostuvimos que lo propio de los principios jurídicos -a diferencia de las reglas- residía en la configuración abierta de sus condiciones de aplicación. De acuerdo con ello, parafrasearemos ahora el art. 20.1 de la siguiente forma: «A menos que, en un determinado caso (genérico o individual), sean aplicables principios que ordenen otra cosa y que, 
en relación con dicho caso, tengan un mayor peso, está permitido expresar o no expresar, difundir o no difundir, cualquier pensamiento, idea, opinión o información». Pues bien ¿es esta formulación (a la que llamaremos E1) equivalente a esta otra (E2): "A menos que, en un determinado caso (genérico o individual), sean aplicables principios que ordenen otra cosa y que, en relación con dicho caso, tengan un mayor peso, esta prohibido al legislador $\mathrm{y}$ en general a los poderes públicos imponer obligaciones o prohibiciones relativas a las conductas consistente en expresar o no expresar, difundir o no difundir, cualquier pensamiento, idea, opinión o información o aplicar sanciones como consecuencia de estas conductas?» A nuestro juicio ambas formulaciones no son equivalentes, por la sencilla razón de que la primera (E1) puede servir de fundamento justificativo a la segunda (E2), mientras que la inversa no se da. Tiene perfecto sentido decir que la Constitución española considera que el que la expresión y difusión de pensamientos, ideas, etc. sea libre es algo valioso y, en consecuencia, impone a los poderes públicos la prohibición de interferir con ellas (salvo que sean aplicables al caso de que se trate y en relación con él tengan un mayor peso principios que ordenen otra cosa y que, en consecuencia, justifiquen la interferencia). En cambio, no parece que tenga mucho sentido decir que la Constitución española considera como valiosa la prohibición de no interferencia de los poderes públicos en materia de expresión y difusión de pensamientos, ideas, etc. y, en consecuencia, permite la expresión y difusión de los mismos. En resumen: el permiso constitucional no es, a nuestro juicio, equivalente a un principio de mandato de no interferencia; lo que ocurre más bien, es que del permiso constitucional se deriva el correspondiente principio de mandato.

Desde el punto de vista de su uso en un razonamiento práctico, la diferencia entre el enunciado E1 y E2 podría exponerse así. Quien partiera de que la libertad de expresión puede expresarse sin pérdida de sentido en enunciados como E2 estaría aceptando que la razón por la que se puede manifestar libremente las propias ideas está constituida precisamente por la existencia de esa norma. A la pregunta de «¿por qué puedo expresar libremente mis opiniones sin que nadie pueda impedírmelo?» o «¿por qué el legislador no puede establecer una norma que incluya restricciones a esa libertad?», la contestación sería que así lo establece E2. Sin embargo, quien considerara que la libertad de expresión se plasma más bien en enunciados como E1 no diría solamente que E1 constituye una razón para expresarse libremente, sino también que E1 presupone que existen razones que justifican ese tipo de conducta. Por eso, a la pregunta de « ¿por qué puedo expresar mis opiniones sin que nadie pueda impedírmelo?», la respuesta no se agota con apelar a E1, sino que incluye también una referencia a un juicio de valor del tipo de «puedo manifestar libremente mis opiniones porque la libertad de expresión es un componente esencial de la autonomía personal y de la democracia política». Dicho con las categorías de Carlos $\mathrm{Nino}^{10}$, E1, esto es, un

${ }^{10}$ Cfr. Nino (1985). 
permiso constitucional, no expresaría simplemente una prescripción -una norma-, sino también un juicio de valor. A esto cabría objetar que si la diferencia entre juicios de valor y prescripciones estriba básicamente en que quien emite un juicio de valor expresa que existen razones que lo sustentan, entonces parecería casi una contradicción hablar de un juicio de valor establecido por medio de un acto de autoridad. Ahora bien, en nuestra opinión, esa objeción queda salvada cuando se piensa en lo siguiente: En el caso de las prescripciones, el acto de la autoridad tiene carácter constitutivo; existen prescripciones porque existen actos de prescribir por parte de las autoridades. Sin embargo, las autoridades no pueden crear los valores, sino simplemente reconocerlos.

Esa capacidad, o esa necesidad, de remontarse mas allá en el razonamiento (en definitiva, su naturaleza de juicio de valor) es también lo que explica que la fuerza expansiva de E1 -de los permisos constitucionales- no se agote en enunciados como E2- en los correspondientes principios de mandato. Por supuesto, un enunciado como E1 tiene, desde el punto de vista de la interpretación de los principios y normas del ordenamiento, una mayor fuerza expansiva que E2. Pero además, los enunciados permisivos constitucionales «se traducen» en el ámbito normativo no sólo en principios de mandato, sino también en directrices. Esto puede verse con claridad si se pone en relación el art. 20.1 con el 9.2. De la combinación de ambos cabe extraer un enunciado (E3) como el siguiente: «Los poderes públicos deben adoptar aquellas medidas que sean idóneas para que el individuo y los grupos en que se integra tengan posibilidades reales y efectivas de expresar y difundir sus pensamientos, ideas, etc.» En nuestra opinión, mientras que E2 expresa un principio en sentido estricto -que ordena a los poderes públicos, en los casos en los que el principio prevalece frente a principios que jueguen en sentido opuesto, omitir cualquier forma de conducta que constituya una interferencia en la libertad de expresión- E3 expresa una directriz o norma programática. Estas normas, a diferencia de los principios en sentido estricto, no ordenan ni prohíben ninguna forma determinada de conducta. Señalan tan sólo la obligatoriedad de perseguir determinados fines, determinados estados de cosas, pero dejan a la discreción de su destinatario (por lo que nos interesa, a la discreción del legislador y, en general, de los poderes públicos) la selección de los medios idóneos para ello. De esta forma, mientras que el principio que prohíbe la interferencia en la libre expresión constituye un límite para los objetivos que pueden perseguirse en el proceso legislativo y político en general, la directriz que ordena perseguir la finalidad de que los individuos y grupos tengan la posibilidad real de expresarse estipula un objetivo que el 
legislador y quienes participan en general en el proceso político no pueden (legítimamente) no querer, pero deja indeterminada (esto es, encomienda su resolución al proceso legislativo y político ordinario) la cuestión de cuáles son las medidas que maximizan la consecución de este objetivo.

\section{Algunas conclusiones}

La conclusión fundamental que se extrae de todo lo anterior es que el significado de los permisos varía en cada uno de los tres contextos que hemos distinguido y que es esta variedad de contextos de uso (y no la distinción entre permiso débil y permiso fuerte) lo que resulta esencial. Vistos exclusivamente como operadores de una regla regulativa, los permisos pueden traducirse enteramente en términos de aclaración (mediante definiciones), de excepción, de derogación o de formulación indirecta de normas de mandato. Expresan la ausencia de una razón perentoria (aclarando que efectivamente no existe o cancelándola) para efectuar o no un determinada conducta y, eventualmente, prohíben a las autoridades subordinadas la introducción de tales razones (esto es, de normas de mandato).

En el contexto del ejercicio de poderes normativos hay que distinguir según que el operador «permitido» modalice el resultado normativo o la acción que es condición necesaria (y eventualmente suficiente) de la producción de ese resultado. En el primer caso, los permisos pueden traducirse en términos de derogación o simplemente negación de normas de mandato, pero su función no es sólo la de expresar la ausencia de razones operativas. En su relación con la regla que confiere poder, cumplen también la función de cualificar como problemática la razón hipotética constituida por la regla que confiere poder. En el segundo caso (cuando «permitido» se refiere a la acción) el permiso no tiene carácter deóntico, sino que expresa una posibilidad anankástica, que para sus usuarios se traduce en una posibilidad técnico institucional. Finalmente, los permisos constitucionales no son sólo normas, sino también juicios de valor. De ellos se derivan principios de mandato y directrices, pero no equivalen a normas de mandato, porque su fuerza expansiva es notablemente mayor. 


\section{REFERENCIAS}

Alchourrón, Carlos y Bulygin, Eugenio (1974): Introducción a la metodología de las ciencias jurídicas y sociales, Astrea, Buenos Aires.

Alchourrón, Carlos y Bulygin, Eugenio (1991): Análisis lógico y Derecho, prólogo de G. H. von Wright, Centro de Estudios Constitucionales, Madrid.

Atienza, Manuel y Ruiz Manero, Juan (1991): «Sobre principios y reglas», en Doxa, nº 10.

Atienza, Manuel y Ruiz Manero, Juan (1992): «Objeciones de principio. Respuesta a Aleksander Peczenik y Luis Prieto Sanchís», en Doxa, no 12.

Atienza, Manuel y Ruiz Manero, Juan (1993): «Tre approcci ai principi di diritto», en Analisi e diritto.

Atienza, Manuel y Ruiz Manero, Juan (1994): «Sulle regole che conferiscono poteri», en Analisi e diritto.

Bayón, Juan Carlos (1991): La normatividad del Derecho. Deber jurídico y razones para la acción, Centro de Estudios Constitucionales, Madrid.

Echave, Delia Teresa, Urquijo, María Eugenia y Guibourg Ricardo (1980): Lógica, proposición y norma, Astrea, Buenos Aires. Alicante.

González Lagier, Daniel (1994): Acción y norma en G. H. von Wright, tesis doctoral inédita,

Guastini, Riccardo (1993): Le fonti del diritto e l'interpretazione, Giuffre, Milano.

Hernández Marín, Rafael (1993): «Double Pairs», en Ratio Juris, vol. 6, nº 3.

Nino, Carlos S. (1985): «¿Son prescripciones los juicios de valor?», en La validez del Derecho, Astrea, Buenos Aires.

Raz, Joseph: Razón práctica y normas, trad. de Juan Ruiz Manero, Centro de Estudios Constitucionales, Madrid.

Ross, Alf (1971): Lógica de las normas, trad. de José S.-P. Hierro, Tecnos, Madrid.

Von Wright, Georg Henrik (1968): «Deontic Logic and the Theory of Conditions», en Crítica, vol. II, no .6 , México.

Von Wright, Georg Henrik (1969): «On the Logic and Ontology of Norms», en J. W. Davis (ed.): Philosophical Logic, Reidel, Dordrecht. Madrid.

Von Wright, Georg Henrik (1979): Norma y acción, trad. de P. García Ferrero, Tecnos, 